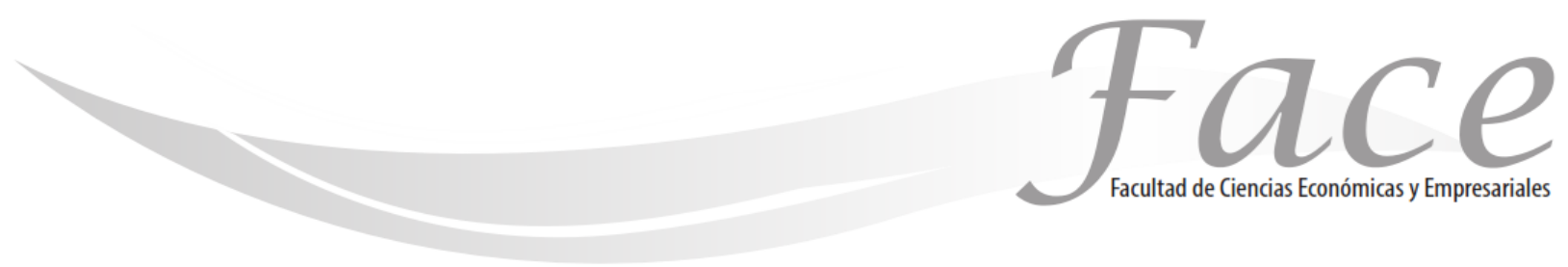

ISSN 1794-9920

Volumen $15-2$

Año 2015

Págs. $117-130$

\title{
EFECTOS TRIBUTARIOS DE LA INCLUSIÓN LABORAL DE PERSONAS CON DISCAPACIDAD EN LAS EMPRESAS DEL SECTOR DE LA ARCILLA DE CÚCUTA Y SU ÁREA METROPOLITANA *
}

\author{
Carlos Alberto Carrillo Pacheco* \\ Betsy Zulay Rondón Niño**
}

Fecha de Recepción: 9 de Octubre 2015

Fecha de Aprobación: 20 de Diciembre 2015

\begin{abstract}
Resumen:
Debido a que Colombia está adscrita a la Convención Internacional sobre los Derechos de las personas con Discapacidad, el poder legislativo y sus gobernantes han desarrollado políticas fiscales orientadas a estimular la implementación de programas para la inclusión laboral de personas con discapacidad. Basados en los resultados del impacto de las políticas fiscales de los beneficios tributarios creados para tal fin, en las empresas del sector industrial de la arcilla en Cúcuta y su área metropolitana, se evaluaron las implicaciones del efecto tributario que han tenido en las empresas por la inclusión laboral de una población que se encuentra en condiciones de discapacidad, la cual necesita una estabilidad laboral y económica que permitan cumplir con las necesidades de todo ser humano. Se propone a los gobernantes una adecuada complementación e implementación entre lo laboral y los beneficios tributarios, con el fin de cambiar la cultura socioeconómica de nuestra región.
\end{abstract}

Palabras Claves: Discapacidad, inclusión laboral, beneficios tributarios, equidad y progresividad.

\footnotetext{
* Articulo resultado del trabajo de grado de la Maestría en Tributación y Política Fiscal de la Universidad de Medellín, en convenio con la Universidad Libre Seccional Cúcuta.

* Contador Público, Universidad Francisco de Paula Santander, Cúcuta; Especialista en Gerencia Tributaria, Universidad Libre de Cúcuta; Maestrante en Tributación y Política Fiscal de la Universidad de Medellín en convenio con la Universidad Libre Seccional Cúcuta. Profesor y asesor tributario externo, Universidad de Pamplona. Correo electrónico: cacarrillop@contapublico.com.

"* Administradora de Empresas Agropecuarias, Universidad Santo Tomás de Aquino; Especialista en Gerencia Tributaria, Universidad Libre de Cúcuta; Maestrante en Tributación y Política Fiscal de la Universidad de Medellín en convenio con la Universidad Libre Seccional Cúcuta. Funcionaria de la División de Gestión de Recaudo y Cobranzas de la Dirección de Impuestos y Aduanas Nacionales (DIAN). Correo electrónico: brondonn@dian.gov.co.
} 


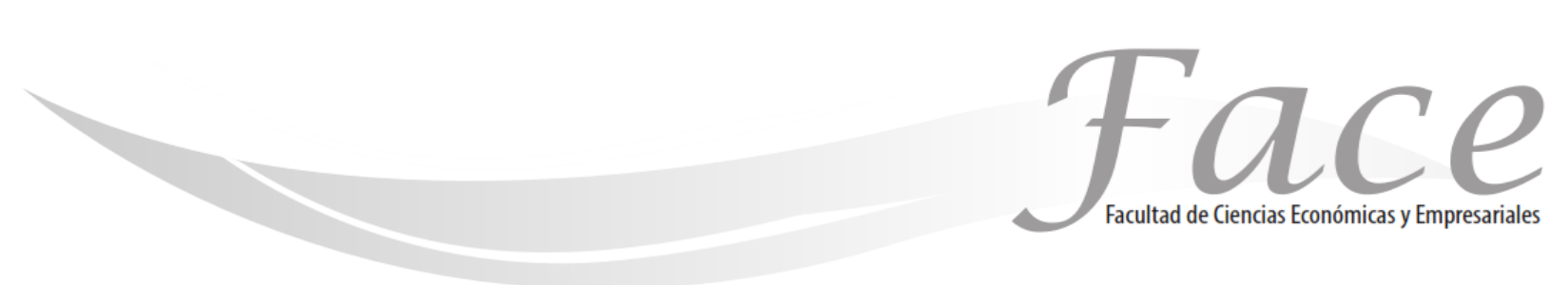

\title{
TAX EFFECT OF THE LABOR INCLUSION OF PEOPLE WITH DISABILITIES IN THE CLAY INDUSTRY OF CÚCUTA AND ITS METROPOLITAN AREA
}

\begin{abstract}
:
As Colombia is attached to the International Convention on the Rights of Persons with Disabilities, its legislative body and government members have developed fiscal policies to stimulate the implementation of programs in order to promote labor market integration of persons with disabilities. Based on the results of the fiscal policy and the tax benefit for the inclusion of disabled people in the clay industry workforce in the city of Cúcuta and its metropolitan area, the study shows that disabled people need job and economic stability, therefore, the present study proposes an adequate complementation and implementation between the labor market policy and tax benefit system in order to change the region's socio-economic culture.
\end{abstract}

Keywords: Disability, Labor Inclusion, Tax Benefits, Equity and Progressiveness.

\section{EFEITOS TRIBUTÁRIOS DA INCLUSÃO LABORAL DAS PESSOAS COM DEFICIÊNCIA NAS EMPRESAS DO SETOR DE ARGILA DE CÚCUTA E SUA ÁREA METROPOLITANA}

\begin{abstract}
Resumo:
Devido a que Colômbia pertence à Convenção Internacional sobre os Direitos das Pessoas com Deficiência, o poder legislativo e seus governantes desenvolveram políticas fiscais para estimular programas para a inclusão laboral das pessoas com deficiência. Baseado nos resultados do impacto das políticas fiscais dos benefícios tributários, nas empresas do sector industrial da argila em Cúcuta e sua área metropolitana, avaliaram-se as implicações do efeito tributário nas empresas pela inclusão laboral de uma população que se encontra em condição de deficiência, na qual necessita de uma estabilidade laboral e econômica que permita responder às necessidades de cada ser humano. Propomos aos governos uma adequada complementação e implantação entre a politica laboral e os benefícios fiscais, com o objetivo de modificar a cultura socioeconômica da nossa região.
\end{abstract}

Palavras-Chave: Deficiência, Inclusão Laboral, Benefícios Tributários, Equidade e Progressividade. 


\section{INTRODUCCIÓN:}

Las políticas actuales de discapacidad del Gobierno Nacional de Colombia, tienen como objetivo principal alcanzar algunos de los derechos fundamentales consagrados,en la Constitución Política de Colombia(1991).En su artículo 13 plantea:

Todas las personas nacen libres e iguales ante la ley, recibirán la misma protección y trato de las autoridades y gozarán de los mismos derechos, libertades y oportunidades sin ninguna discriminación por razones de sexo, raza, origen nacional o familiar, lengua, religión, opinión política o filosófica. El Estado promoverá las condiciones para que la igualdad sea real y efectiva y adoptará medidas en favor de grupos discriminados o marginados. El Estado protegerá especialmente a aquellas personas que por su condición económica, física o mental, se encuentren en circunstancia de debilidad manifiesta y sancionará los abusos o maltratos que contra ellas se cometan (Constitución política de Colombia, 1991).

Una de las causas que origina la importancia, de la solicitud del gobierno Nacional,sobre la relevancia de incluir laboralmente a las personas con discapacidad, es que la Convención Internacional sobre los Derechos de las personas con Discapacidad, en su artículo 27 resalta lo siguiente "Los Estados partes, reconocen el derecho de las personas con discapacidad a trabajar, en igualdad de condiciones con las demás; ello incluye el derecho a tener la oportunidad de ganarse la vida mediante un trabajo libremente elegido o aceptado en un mercado y un entorno laboral que sean abiertos, inclusivos y accesibles a esta población" (Convención Internacional sobre los derechos de las personas con discapacidad, 2006, pág. 22)

Por lo tanto, el Gobierno Nacional, los departamentos, municipios, comités de discapacidad y la sociedad en general, han hecho extensiva la inclusión laboral de las personas con discapacidad a través de los programas especiales, en los diferentes departamentos de Colombia.
Así mismo, también cabe destacar la problemática de desempleo de las personas que se encuentran con discapacidad en Colombia y especialmente en Cúcuta y su área metropolitana, dado que se estima que en un $6,7 \%$ de la población del Norte de Santander presenta alguna condición de discapacidad. Es decir, más de 41.000 personas (La opinión, 2013). Paralelamente, se confrontó con datos oficiales del DANE donde muestran un total para Cúcuta de 6.798 personas en condición de discapacidad a marzo de 2010, de los cuales se tiene información de 905 personas que se encontraban realizando una actividad económica, siendo en su mayoría el informalismo del comercio, como es ya costumbre en esta zona de frontera(Dane, 2010).

Con la intención de establecer en Norte de Santander y en especial en Cúcuta y su área metropolitana, la efectividad y justificación de las políticas públicas que se puedan desarrollar a favor de la inclusión laboral de personas con discapacidad. Este artículo tiene como objetivo analizar el efecto tributario en la inclusión laboral para personas con discapacidad, en las empresas del sector industrial de la arcilla. Para llevar a cabo lo anterior, se realizó la revisión bibliográfica con el fin de desarrollar un marco teórico, como base primordial del trabajo de campo realizado en las empresas del sector industrial de la arcilla, analizando la información y dejando unas propuestas para que se materialice el objetivo de los beneficios fiscales para la inclusión laboral de personas con discapacidad.

Las ciudades principales de Colombia, como Bogotá, Medellín, Cali y Pereira han avanzado hace unos años en este aspecto con programas desarrollados por iniciativas y alianzas con entidades como el Banco Interamericano de Desarrollo BID, la Fundación Corona, el Servicio Nacional de Aprendizaje SENA, la Agencia Presidencial de Cooperación Internacional de Colombia - APC y la Fundación Saldarriaga Concha. Juntos desarrollaron la propuesta de trabajo "Programa de inclusión Laboral Productiva para Personas con discapacidad", que fue aprobada por el Fondo Multilateral de Inversiones del BID, en noviembre de 2008. (Pacto deProductividad, 2014). 
Teniendo en cuenta el desarrollo que ha tenido el tema en otras ciudades del país, este estudio se hace necesario porque se realiza un análisis estadístico en cuanto a la gestión de los beneficios tributarios existentes en la legislación actual, en las empresas del sector de la arcilla, tan importante para la economía Departamental. Adicionalmente, con los resultados de esta investigación, se verán beneficiadas,tantos las empresas, al conocer los efectos de una manera amplia, directa y actualizada de las políticas que regulan en materia tributaria los beneficios que pueden tener al contratar personal discapacitado, como la población desempleada de personas con discapacidad que desean tener una oportunidad para demostrar que son muy buenos trabajadores.

Finalmente, cabe preguntar si realmente, son viables las políticas fiscales que tiene actualmente el Gobierno Nacional, como son, los compromisos para la implementación de políticas que favorecen a las personas con discapacidad, así como también a las empresas que participen dela inclusión laboral de esta población tan vulnerable. Así como también, los lineamientos y estrategias de instituciones del Estado en la construcción de políticas públicas de inclusión laboral de personas con discapacidad.

\section{Antecedentes}

Por otra parte, se debe identificar la situación de la discapacidad en Colombia, para ello la información estadística y de investigación disponible permite al Estado y los gobernantes tanto nacionales como departamentales, aplicar políticas,regulada a partir de lo que menciona la ley 1346 de 2009, la cual aprueba la Convención sobre los Derechos de las personas con discapacidad en Colombia,en su artículo 31 dispone:

Los Estados Partes recopilarán información adecuada, incluidos datos estadísticos y de investigación, que les permita formular y aplicar políticas, siempre y cuando respeten las garantías legales, cumplan con las normas aceptadas internacionalmente y se aseguren que sean accesibles para las personas con discapacidad" (Ley 1346 de 2009).

La gestión pública en discapacidad debe responder entre otras normas a los compromisos del Estado de cara a la "Convención sobre los Derechos de las Personas con Discapacidad", promoviendo y protegiendo los derechos y la dignidad de las personas, impulsando el desarrollo social, y la no discriminación. "El Estado Colombiano debe garantizar a las personas el disfrute pleno de los derechos, el grado de aplicación determina en los territorios su grado de desarrollo social y económico, pues sólo en los municipios los derechos se hacen efectivos." (Beltran, 2010).

Como definición de las personas con discapacidad,se encuentra que en la Convención Internacional de los derechos de las personas con discapacidad, las menciona en su artículo $1^{\circ}$ denominándolas como "... aquellas que presentan deficiencias físicas, mentales, intelectuales 0 sensoriales a largo plazo que, al interactuar con diversas barreras, puedan impedir su participación, que se debe promover, proteger y asegurar el goce pleno y en condiciones de igualdad de todos los derechos humanos y libertades fundamentales por todas las personas con discapacidad, y promover el respeto de su dignidad inherente". (Convención Internacional sobre los derechos de las personas con discapacidad, 2006, pág. 22).

El Ministerio de Protección Social es actualmente el ente que articula al Sistema Nacional de Discapacidad (SND), la cual con sus, normas, actividades, recursos, programas logran promover e implementar políticas públicas en discapacidad, en forma ordenada con las entidades públicas nacionales, los comités de discapacidad y la sociedad civil, con el fin de garantizar sus derechos fundamentales(ley 1145 del 10 de julio de 2007).

Así mismo,el Ministerio tiene actualmente la competencia de realizar el Registro para la Localización y caracterización de personas con Discapacidad, informando con corte de diciembre de 2013,que 1'062.917 colombianos se han inscrito en el RLCPD, de las cuales 545.876 son mujeres y 516.030 son hombres(Ministerio de salud y protección social, 2013).

Del mismo modo, en el año 2010 el DANE realizó un último estudio caracterizando y localizando a la población discapacitadas, allí encontró que en Cúcuta y su área metropolitana el $29.75 \%$ de un total de 3842 personas con discapacidad en el departamento estaban trabajando, en contraste con las personas con discapacidad que buscaba empleo, siendo este de un $45 \%$, muchas veces por la falta de ofertas laborales y discriminación por ciertos paradigmas culturales que tienen esta población para el acceso al empleo.(Dane, 2010) 
Cuadro $\mathrm{N}^{\circ} 1$

Población de 10 Años y Más con registro para la localización y caracterización de las personas con discapacidad por actividad principal, según municipio.

\begin{tabular}{|c|c|c|c|c|c|c|c|c|c|c|c|c|}
\hline Municipios & Total & Trabajando & $\begin{array}{l}\text { Buscand } \\
\text { o trabajo }\end{array}$ & \begin{tabular}{|l|} 
Incapacitado \\
permanente \\
para trabajar \\
-sin pensión \\
\end{tabular} & \begin{tabular}{|l|} 
Incapacitado \\
permanente \\
para trabajar \\
\\
- con pensión \\
\end{tabular} & \begin{tabular}{|c} 
Estudi \\
ando
\end{tabular} & $\begin{array}{c}\text { Realizando } \\
\text { oficios del } \\
\text { hogar }\end{array}$ & $\begin{array}{c}\text { Recibiendo } \\
\text { renta }\end{array}$ & $\begin{array}{c}\text { Pensionad } \\
0 \\
\text { - jubilado }\end{array}$ & \begin{tabular}{|} 
Realizando \\
actividade \\
de \\
autoconsu \\
mo
\end{tabular} & $\begin{array}{c}\text { Otra } \\
\text { activid ad }\end{array}$ & \begin{tabular}{|c|} 
Sin \\
inform \\
ación
\end{tabular} \\
\hline TOTAL NORTE DE SANTANDER & 23.636 & 3842 & 1310 & 7534 & \begin{tabular}{|r|}
533 \\
\end{tabular} & 1166 & 4741 & 150 & 153 & 900 & 1687 & 1620 \\
\hline 54001 CÚCUTA & 6541 & 940 & 548 & 2512 & 168 & 267 & 588 & 103 & 88 & 366 & 576 & 385 \\
\hline 54261 EL ZULIA & 428 & 45 & 4 & 211 & 5 & 11 & 35 & 0 & 0 & 15 & 40 & \\
\hline 54 405 LOS PATIOS & 1130 & 137 & 28 & 332 & 29 & 47 & 189 & 3 & 17 & 37 & 211 & 100 \\
\hline 54874 VILLA DEL ROSARIO & 146 & 21 & 10 & 63 & 4 & 3 & 18 & 0 & 0 & 0 & 17 & \\
\hline
\end{tabular}

Fuente: Elaboración Propia

El $67,36 \%$ de la personas con discapacidad que trabajan lo hacen en su gran totalidad en el comercio muchas veces informal sin ningún tipo de seguridad social ni prestaciones sociales, por ser un territorio fronterizo, en donde según estudiosde la cámara de comercio de Cúcuta "el mercado laboral del municipio de Cúcuta y su área metropolitana, está caracterizado por tener 603.000 personas en edad de trabajo es decir, $77,7 \%$ de la población en total del área metropolitana".(Camara de Comercio de Cúcuta, 2013, pág. 4).

En un estudio de la situación del mercado laboral de Cúcuta en el 2011, William Avendaño explica que de las estadísticas de la cámara de Comercio de Cúcuta, en donde existe una población activa de 401.000 personas y de estos, 340.000 personas se encuentran ocupadas (86.7\%) y 60.000 desocupadas (13,3\%), aclarando que de las 340.000 personas ocupadas 224.000 son informales mientras que 116.000 son formales, ocupando el municipio el segundo lugar en informalidad en Colombia. Concluyendo que las 224.000 personas laboralmente activas no reciben como producto de su trabajo las prestaciones sociales necesarias que el orden jurídico exige garantizarles.(Avendaño C, 2012, pág. 195)

Esta situación continua, como puede verse en las estadísticas del DANE, en enero de 2015, donde la tasa de desempleo fue $9,5 \%$,las tres ciudades con más alto desempleo fueron Armenia (17,1\%), Quibdó $(17,0 \%)$ y Cúcuta AM (16,1\%).En contraste las ciudades con menor tasa de desempleo fueron: Montería $(7,3 \%)$, Bucaramanga AM(8,5\%)y Bogotá DC (8,6\%) (Dane, 2015).

Según el Departamento Administrativo Nacional de Estadísticas (Dane), la tasa de desocupación en Cúcuta, Villa del Rosario, Los Patios y El Zulia fue de 16,1 por ciento durante el trimestre móvil febrero -abril de 2015.
Este índice es inferior al 16,7 por ciento reportado en el trimestre móvil enero-marzo. (Dane, 2015).

\section{MARCO TEÓRICO:}

El marco normativo y político sobre discapacidad tanto internacional como nacional, reconoce la necesidad que se presenta ante las limitaciones existentes en las empresas y en la cotidianidad de las personas con discapacidad, tratando de fortalecer y avanzar a través de las políticas públicas, de las diferentes instituciones articuladas, para garantizar la igualdad de los derechos de la población con discapacidad.

Debido a la Ratificación que realizó Colombia, de la Convención de Naciones Unidas mediante la Ley 1346 de 2009, se observa, que las políticas públicas se desarrollan para la protección y estrategias para prevenir riesgos, discriminaciones, exclusión, para las personas, familia, organizaciones y empresas.

Dentro del marco legal internacional y nacional, las declaraciones, pactos y la Constitución Política de 1991 presentan una serie de artículos que hacen referencia al apoyo, cuidado protección e integración social de las personas con discapacidad representados en el siguiente cuadro: 


\begin{tabular}{|c|c|}
\hline MARCO LEGAL INTERNACIONAL & MARCO LEGAL CONSTITUCIONAL \\
\hline $\begin{array}{l}\text { Declaración Universal de los Derechos } \\
\text { Humanos adoptada en } 1948 \text { por la Asamblea } \\
\text { General de las Naciones Unidas. }\end{array}$ & $\begin{array}{l}\text { Artículo } 13^{\text {. }} \ldots \text {...El Estado protegerá especialmente a } \\
\text { las personas que por su condición económica, } \\
\text { física o mental, se encuentren en circunstancia de } \\
\text { debilidad manifiesta y sancionará los abusos o } \\
\text { maltratos que contra ellas se cometan" }\end{array}$ \\
\hline $\begin{array}{l}\text { Pacto Internacional de Derechos Económicos, } \\
\text { Sociales Culturales"-1976 }\end{array}$ & $\begin{array}{l}\text { Artículo 47: "El Estado adelantará una política de } \\
\text { previsión, rehabilitación e integración social para } \\
\text { los disminuidos físicos, sensoriales y psíquicos, a } \\
\text { quienes se prestará la atención especializada que } \\
\text { requieran". }\end{array}$ \\
\hline $\begin{array}{l}\text { Pacto Internacional de Derechos Civiles y } \\
\text { Políícos (1976). }\end{array}$ & $\begin{array}{l}\text { Artículo 54:"El Estado debe...garantizar a los } \\
\text { minusválidos el derecho a un trabajo acorde con } \\
\text { sus condiciones de salud". }\end{array}$ \\
\hline $\begin{array}{l}\text { Declaración de Derechos de las personas con } \\
\text { retardo mental (1971), }\end{array}$ & $\begin{array}{l}\text { Artículo } 68 . . . . . \text { La erradicación del analfabetismo y } \\
\text { la educación de personas con limitaciones físicas o } \\
\text { mentales,...son obligaciones especiales del } \\
\text { Estado". }\end{array}$ \\
\hline Declaración de los Derechos de los Impedidos & $\begin{array}{l}\text { Así mismo la Constitución Política define una serie } \\
\text { de derechos fundamentales, sociales, económicos } \\
\text { y culturales, que son de carácter universal y por } \\
\text { tanto cubren a quienes presenten algún tipo de } \\
\text { limitación o discapacidad. Entre ellos encontramos: }\end{array}$ \\
\hline $\begin{array}{l}\text { Declaración sobre las Personas Sordo-Ciegas } \\
\text { (1979). }\end{array}$ & $\begin{array}{l}\text { Artículo 25: Hace mención al trabajo como derecho } \\
\text { y obligación social, que se debe dar bajo } \\
\text { condiciones dignas y justas. }\end{array}$ \\
\hline
\end{tabular}

Fuente: Elaboración propia con base en Pactos, declaraciones internacionales y la Constitución de Colombia de 1991.

Colombia ha adaptado sus instituciones y políticas en los últimos 13 años, a los tratados y convenciones internacionales para dar cumplimiento de la convención de las Naciones Unidas, implementando leyes y planes nacionales en política pública, con los siguientes antecedentes normativos: 
EFECTOS TRIBUTARIOS DE LA INCLUSIÓN LABORAL DE PERSONAS CON DISCAPACIDAD EN LAS EMPRESAS DEL SECTOR DE LA ARCILLA DE CÚCUTA Y SU ÁREA METROPOLITANA

Carlos Alberto Carrillo Pacheco - Betsy Zulay Rondón Niño

Cuadro $N^{\circ} 3:$

Leyes y políticas sobre Discapacidad en Colombia.

\begin{tabular}{|c|c|}
\hline AÑO & $\begin{array}{l}\text { LEYES Y POLITICAS IMPLEMENTADASSOBRE LAS PERSONAS CON DISCAPACIDAD EN } \\
\text { COLOMBIA }\end{array}$ \\
\hline Año 2002: & $\begin{array}{l}\text { La ley } 762 \text { de } 2002 \text { aprueba la "Convención interamericana para la Eliminación de todas las formas de } \\
\text { Discriminación contra las personas con Discapacidad }\end{array}$ \\
\hline Año 2004: & $\begin{array}{c}\text { El Documento Conpes } 80 \text { de } 2004 \text { denominado Política Pública Nacional de Discapacidad, crea el } \\
\text { enfoque de Manejo Social de Riesgo. }\end{array}$ \\
\hline Año 2007: & La ley 1145 de 2007, por medio de la cual se organiza el sistema nacional de discapacidad. \\
\hline Año 2009: & $\begin{array}{l}\text { La ley } 1346 \text { de 2009, por medio de la cual se aprueba a convención sobre los derechos de las } \\
\text { personas con Discapacidad. }\end{array}$ \\
\hline Año 2010: & Se crea el Plan nacional de Desarrollo 2010-2014: Prosperidad para Todos. \\
\hline Año 2011 y 2012 & $\begin{array}{l}\text { Se realizó la Evaluación institucional de la política nacional de discapacidad complementada con una } \\
\qquad \text { evaluación de resultados cualitativos sobre }\end{array}$ \\
\hline Año 2013: & $\begin{array}{l}\text { Ley estatutaria } 1618 \text { de } 2013 \text { :La cual establece las disposiciones para garantizar el pleno ejercicio de } \\
\text { los derechos de las personas con discapacidad y se crea la política Pública Nacional de Discapacidad } \\
\qquad \text { e inclusión social y Conpes Social } 166 \text { de } 2013\end{array}$ \\
\hline
\end{tabular}

Fuente: Elaboración Propia.

\section{Beneficios tributarios para la inclusión laboral de personas con discapacidad}

El objetivo principal del gobierno nacional y el de sus instituciones,al crear en la legislación tributaria colombiana una serie de tarifas diferenciales, haciendo referencia a diversos beneficios que involucran diferentes objetivos económicos, entre otros, es el desarrollo de las regiones, la generación de empleo, la promoción de algunos sectores económicos, el desarrollo tecnológico, la protección y conservación ambiental y el fomento a la inversión nacional o extranjera(Ministerio de hacienda, 2013).
En el desarrollo de este análisis investigativo, se utiliza como herramienta el normograma, aplicación dinámica que facilita, la comprensión de la ejecución de los diversos beneficios ofrecidos por la ley, sean estos tributarios 0 de otra índole que por obvias razones no se ven relacionados en el mismo. Es indispensable hacer uso de esta utilidad ya que de acuerdo a ello se enfocó el cuestionamiento que sirvió de análisis dándole rumbo a la idea del aprovechamiento de los beneficios planteados. 
ISSN: 1794-9920 Julio - Diciembre 2015

Es de resaltar que la función específica de este normograma formulado permite profundizar las posibles causas de la aplicación de beneficios, desinterés del mismo, desconocimiento o sencillamente temores y conceptos erróneos para aplicarlos, ya que se trata de justifican costos y/o gastos a la administración tributaria para disminuir la base del impuesto básico de renta.

Un aspecto relevante del normograma planteado en esta investigación es que si bien es cierto la norma en general ofrece varios beneficios, de la cual no todos son de carácter tributario, lo cual, no fueron objeto de la investigación, al tener un carácter tributario, para efectos de esta maestría; pero que sin embargo son tenidos en cuenta para decisiones ya sean administrativas, sociales 0 de otro aspecto que pueda servir de ayuda para fundamentar las conclusiones de esta investigación.
El siguiente cuadro permite ver un enfoque claro y esquematizado del alcance de la normas sobre los beneficios tributarios sobre las personas con discapacidad, clase de tributo, tipo de beneficio, la norma taxativa, el beneficio que aplica, su extensión y requisitos y a quien va dirigido, de manera que los empresarios conozcan sobre la regulación en materia tributaria, a la que pueden acogerse a la hora de realizar la planeación tributaria de sus empresas y a la vez contribuir con la responsabilidad social por la inclusión laboral de la población con discapacidad.

\section{Cuadro $\mathrm{N}^{\circ} 4$ :}

Normograma

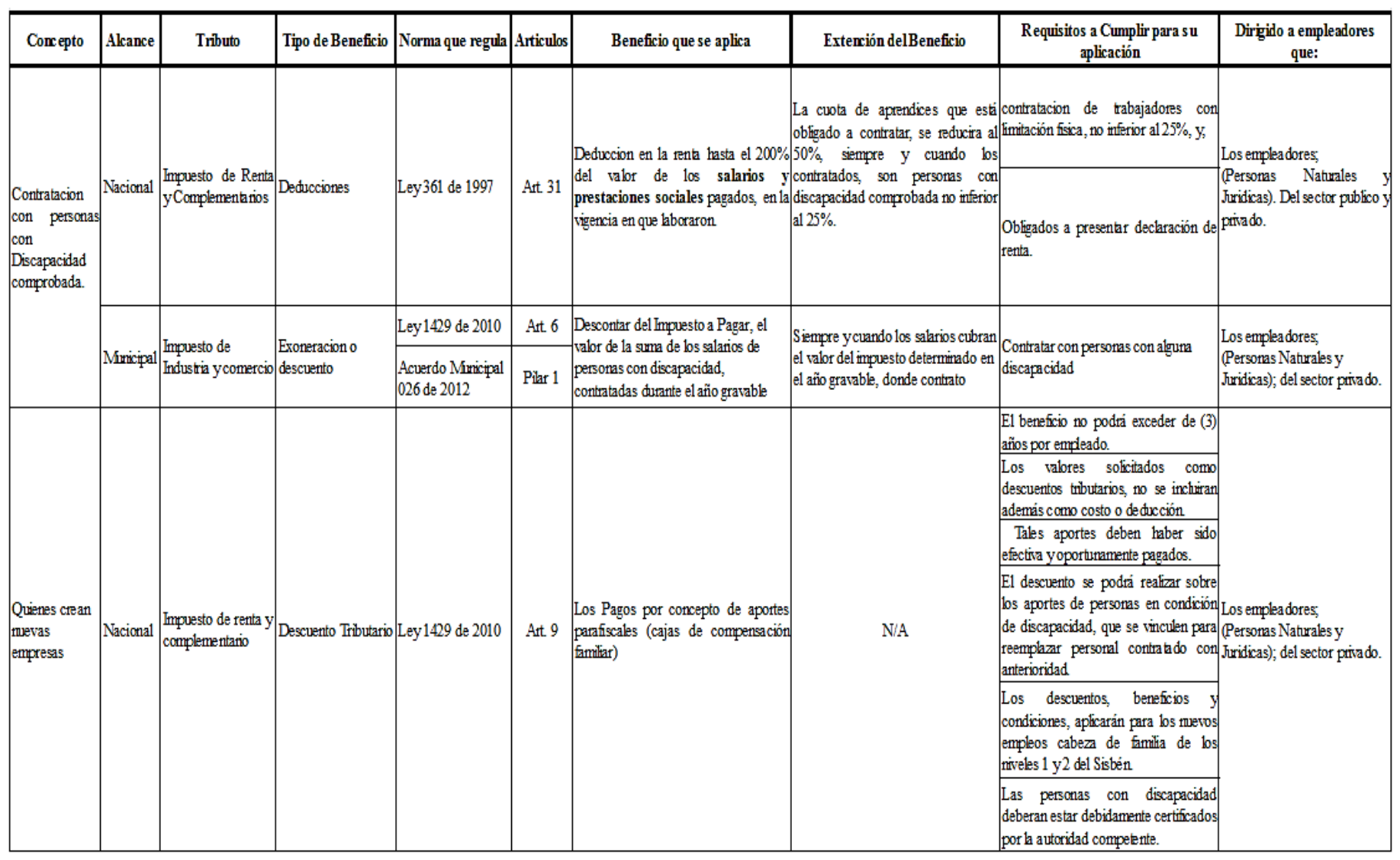

Fuente: Elaboración propia basada en recopilación de normas. 


\section{METODOLOGÍA:}

La investigación tiene un enfoque cualitativo, inicia con la revisión de literatura creando un marco teórico y conceptual sobre la Inclusión de personas con discapacidad, en un contexto internacional, nacional y regional, basándose en la situación económica y social de las personas con discapacidad en Cúcuta y su área metropolitana, así como también se describe la implementación de las políticas fiscales actuales y evaluaciones económicas de los beneficios en general.

Por otra parte, implica la utilización del método cuantitativo, el cual admite la elaboración de una encuesta que sirvió como instrumento para determinar el conocimiento y la utilización del uso de los beneficios tributarios otorgados por la ley de las empresas que contratan laboralmente personas con discapacidad en el sector de la fabricación de materiales de arcilla para la construcción en Cúcuta y su área metropolitana, se utilizó como fuente la Cámara de Comercio de Cúcuta, aportando una base de68empresas, encuesta respondida por los contadores y jefes de personal de las respectivas empresas, se seleccionó este sector Industrial tan representativo en la industria de Norte de Santander, porque participa con el $12,8 \%$ por ciento del Producto Interno Bruto(PIB)y donde los altos costos de mano de obra, representan el $30 \%$ por ciento de los costos totales de las empresas. (G (Gonzalez, 2013) dado que no se encuentran antecedentes sobre una evaluación de inclusión laboral y de políticas fiscal para las personas con discapacidad que puedan aplicarse en este contexto.

En las Encuestas realizadas en el sector de la fabricación de materiales de arcilla para la construcción en Cúcuta y su área metropolitana se pretendía evaluar principalmente sobre el conocimiento de los beneficios tributarios, en la inclusión laboral de personas con discapacidad en dichas empresas y en la percepción que se tiene acerca de las políticas fiscales que tienen como propósito incentivar la vinculación laboral de personas con discapacidad en las empresas.

La encuesta estuvo compuesta de 13 preguntas relacionadas con los siguientes tópicos: Identificación de la empresa, percepción de la inclusión laboral en la empresa, tipos de contrato y los cargos que desempeñaban las personas con discapacidad en las empresas; así como también, el conocimiento delos beneficios tributarios al incluir personas con discapacidad, su aplicación y barreras presentadas al momento de contratar estas personas, por último, se pretende conocer la percepción que se tiene de las políticas fiscales adoptadas por el estado que contribuyen con los propósitos que se crean incentivando la vinculación laboral de personas con discapacidad en las empresas.

Conviene, sin embargo advertir, que al final este estudio es descriptivo y correlacional, porque pretende determinar el efecto tributario que obtendrían las empresas del sector industrial fabricación de materiales de arcilla para la construcción de Cúcuta y su área metropolitana, que vinculen laboralmente personal discapacitado.

\section{RESULTADOS:}

De acuerdo al primer ítem denominado "identificación de la empresa", se analiza en primera medida el objeto social de las empresas encuestadas, donde según el perfil seleccionado el sector industrial de la fabricación de materiales de arcilla, el cual tiene una representación del $77,27 \%$, equivalentes a treinta y cuatro (34) empresas industriales encuestadas, ya sean grandes, medianas y pequeña. Es de resaltar que este proyecto se vio motivado a realizarla en este perfil, debido a que según su proceso productivo, ofrece mayores alternativas de obtención de empleo por parte de personas con discapacidad en esta región en específico.

Es de resaltar que este tipo de empresas industriales, de acuerdo a lo que se pudo observar, son empresas propias de nuestra región convirtiéndose en empresas directas generadoras de empleo, debido a que son sedes principales, representadas en un $95,45 \%$ que se encuentran ubicadas en Cúcuta y su área metropolitana.

Por otro lado, se considera relevante expresar que, de acuerdo a la clasificación de las empresas en Colombia, bajo el concepto del tamaño de la misma, en lo contemplado en el Art. 2 de la Ley 590 de 2000, la determinación de su grandeza tiene como pilar fundamental, "el número o cantidad de trabajadores", (ley 590 de 2000) factor que puntualmente marca la diferencia en justificación de la generación de sus ingresos y sus respectivos costos y gastos que la soportan, adicionado montos de sus activos que estas poseen a su favor. Lo anteriormente expuesto hace referencia a que en un promedio del $10,80 \%$, las empresas industriales posee en sus filas una vinculación entre una (1) a setenta (70) personas, en este sector, y solo un $13.64 \%$ como promedio posee personal vinculado mayores a las ochenta (80) personas. 
Finalizando con la identificación de la empresa, este sector resulta paradójicamente controversial, ya que si bien es cierto, es el sector que más oportunidad laboral ofrece a toda clase de personas, coincidencialmente, en esta clase de sector su presencia tiende a desaparecer, ya que del total del universo a analizar tan solo un sesenta y cuatro con setenta y un porciento $(64,71 \%)$, se pudo analizar a profundidad, dejando al margen un $35,29 \%$ que no fue objeto de análisis ya que cuando se recurrió a ellos, la mayor excusa para su no realización se basó en la liquidación o extinción de las misma.

Por otro lado, en el ítem de percepción de la inclusión laboral en las empresas industriales en el sector de la arcilla, tipos de contrato y los cargos que desempeñaban las personas con discapacidad en las empresas; el análisis realizado a esta situación, que por cierto es el punto de partida en la determinación de nuestro objetivo primordial, demuestra que el eje de todo proceso productivo es la ejecución de la mano de obra, y como tal, este va hacer el actor principal que accionará el efecto al cual se quiere llegar. El resultado de sí las empresas industriales de la arcilla en la ciudad de Cúcuta y su área metropolitana, tienen vinculados laboralmente a esta clase de personas, determinó que tan solo nueve (9) de estas, tiene contratados personas con discapacidad, independientemente de la clase de contratación que posean, es decir, sea por contrato laboral o por prestación de servicios, lo que representa que un $79,55 \%$ del total analizado no posee vinculados a personas con discapacidad, y es ahí donde este análisis se centra, con el fin de determinar cuál es el motivo de tanta indiferencia o desinterés.

Sin embargo, de acuerdo a las nueve (9) empresas industriales de la región, estas poseen un total de veintitrés(23) personas con discapacidad en sus filas laborales, lo que a la vista de esta investigación deja entrever, que aun en menor proporción un $39,13 \%$ es la participación de esta población menos favorecida, respecto a las empresas industriales contratantes. Por lo anterior, se observó también que cinco (5) personas con discapacidad poseen un contrato laboral a término fijo a un año, (3) personas con contrato laboral a término indefinido y una (1) desarrolla sus actividades a destajo, de los cuales un $4,55 \%$ desarrolla actividades administrativas y un $13,64 \%$ se encuentra realizando actividades de producción, lo que ratifica a un más la teoría, que el sector industrial de la arcilla, ofrece posibilidades de contratar personas con discapacidad.

Como se advierte inicialmente en el artículo el factor laboral por la inclusión con personas con discapacidad es el actor que acciona, el tema de esta investigación, de lo cual como se pudo observar es muy poca la intervención que se tiene, pero que sin embargo se produce un origen aunque pequeño, no es el desalentador para lo que se espera en el futuro y aún más que se presente en esta región del país, donde su fuente de recursos, es la explotación de las actividades comerciales en una gran porción.

Por otro lado, en el caso del conocimiento delos beneficios tributarios al incluir personas con discapacidad, su aplicación y barreras presentadas al momento de contratar estas personas, por parte de la empresas industriales de la arcilla en el sector privado, se encontró con sorpresa, que a pesar de que solo nueve (9) de las empresas poseen contratadas personas con discapacidad, quince (15) de estas argumenta al menos, conocer sin profundizar en el tema sobre los beneficios tributarios que se ofrecen en nuestra legislación colombiana. Es de resaltar y tal como lo muestra la gráfica solo tres (3) empresas de este sector hacen uso de los beneficios, pero que sin embargo son temerosos de su resultado en el futuro, ya que como, es muy poca su aplicación en la región, proporcionalmente sienten inseguridad en su aplicación, lo que representa que un porcentaje del $6,82 \%$ le dan aplicabilidad y que por el contrario en un $93,18 \%$ no lo aplican, lo que deduce que de las nueve (9) empresas que contrataron esas 23 personas, infortunadamente seis (6) de las demás empresas industriales en la arcilla no lo aplican, debido a razones tales como falta de un asesor o conocimiento del contador que les organiza, procesa y determina sus saldos contables y tributarios, representados en un $40,91 \%$, falta de divulgación de la norma en un 13,64\%, falta de planeación tributaria en un $9,09 \%$, desinterés $6,82 \%$ y por miedo o inseguridad en aplicar la norma un $29,55 \%$.

\section{Gráfica $N^{\circ} 1$}

Aplicación del Beneficio Tributario por parte de las empresas que vinculan laboralmente a personas con discapacidad.

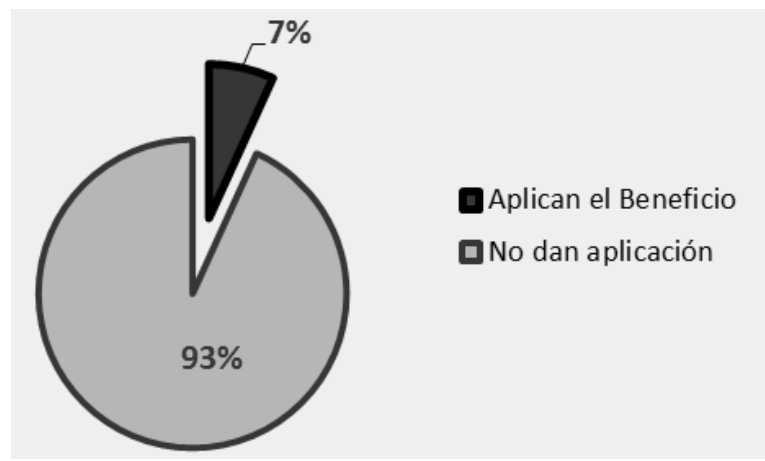

Fuente: Elaboración Propia.

Según lo expuesto anteriormente, tal y como se expresó inicialmente en el normograma, el precepto básico del 
beneficio promulgado por la ley 361 de 1997 en su art. 31 expresa lo siguiente "Los empleadores que ocupen trabajadores con limitación no inferior al $25 \%$ comprobada y que estén obligados a presentar declaración de renta y complementarios, tienen derecho a deducir de la renta el $200 \%$ del valor de los salarios y prestaciones sociales pagados durante el año o período gravable a los trabajadores con limitación, mientras esta subsista.(...).(Ley 361 de 1997)Una de las razones de su aplicabilidad según esta investigación es que todo aquel gasto que incurra un empleador según su denominación por conceptos de salarios y prestaciones sociales sencillamente serán deducidas en el doble, lo que implica que la renta líquida gravable de las empresas que determinan su impuesto por el sistema ordinario, verán afectado su resultado disminuyéndolo, lo que se refiere a que el impuesto básico será menor, este impacto no es tenido en cuenta por los factores anteriormente expuestos.
Ahora bien, si hablamos desde el punto de vista del empresario, el ve afectados los intereses económicos en la razón de que tanto el riesgo laboral, adecuación de la infraestructura, demandas laborales y entre otros factores conllevan a otro tipo de desinterés, que perjudican a un más la contratación de personas con discapacidad, tal y como lo muestra la gráfica.

De acuerdo a lo sustentado por los entrevistados, expresan que una de las razones, de la cual obvian la aplicación de los beneficios tributarios otorgados por la ley, es por la afectación o incremento de las deducciones, de tal manera que disminuye el impuesto determinado, que de acuerdo al precepto del art. 188 del Estatuto tributario, en ningún momento la renta líquida será inferior a la renta presunta. Es decir, que los contribuyentes, al determinar que en sus declaraciones existe una renta presunta superior a la Renta Líquida, no se esfuerzan en planear y controlar su renta líquida, motivo por el cual perdería interés en adoptar tales beneficios tributarios.

Gráfica $\mathrm{N}^{\circ} 2$

Razón para no tener conocimiento de las implementaciones de los beneficios tributarios.

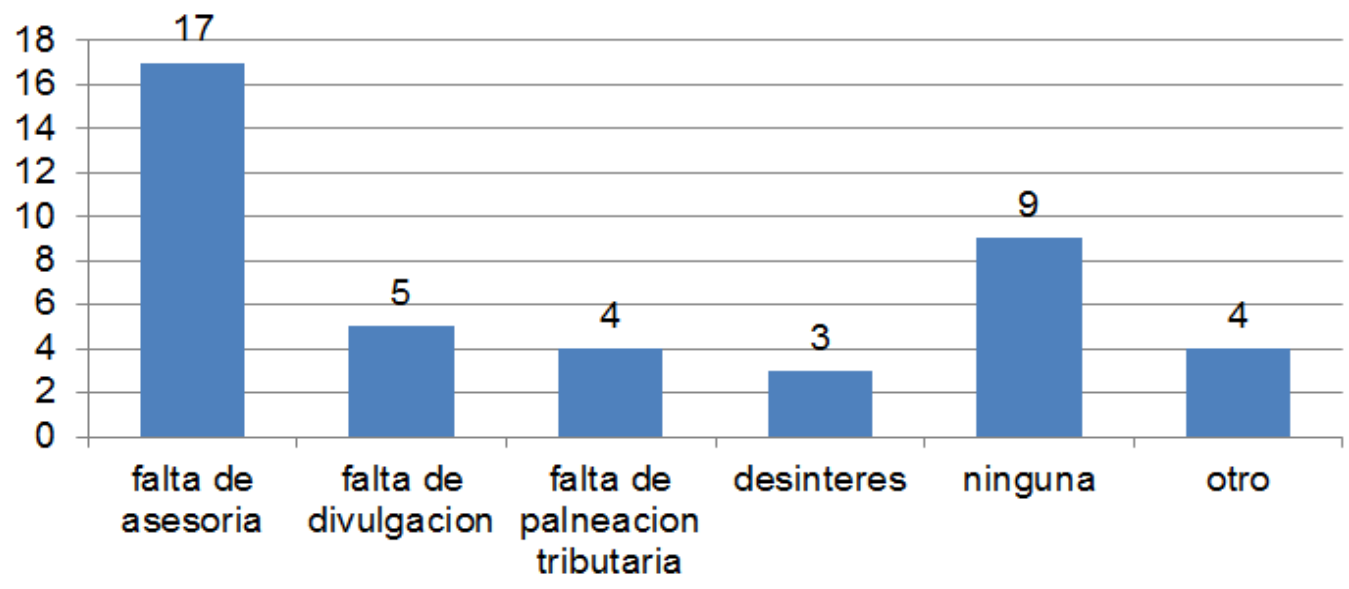

Fuente: Elaboración Propia.

Es de resaltar que las empresas que son objeto de análisis, son industriales en su mayoría, con infraestructura y activos fijos relevantes en su valor, del cual muy seguramente su patrimonio líquido que asu vez es la base de la renta presunta, sería muy elevado lo que conllevaría a la determinación de su impuesto a través de este sistema.
Para Finalizar, producto de este análisis investigativo, una de las aristas o factores del cual, no se da uso o aplicación de los beneficios tributarios ofrecidos por la ley, es que falta asesoría en el tema, motivo por el cual se encontró que un $68,18 \%$, es decir treinta de los encuestados están interesados en profundizar o integrarse en el tema. 
Gráfica $N^{\circ} 3$

Barreras encontradas en la implementación de la utilización de beneficios tributarios de la inclusión laboral de personas

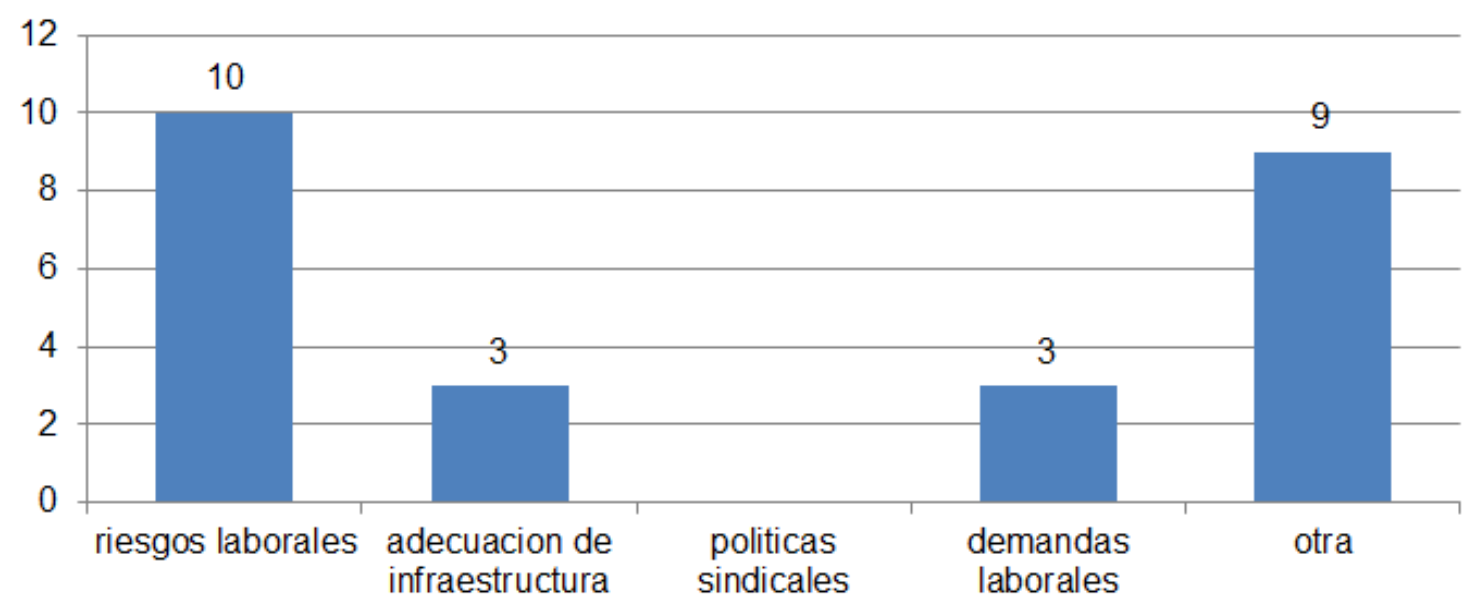

Fuente: Elaboración propia.

\section{CONCLUSIONES:}

Por todo lo anteriormente expuesto, este análisis investigativo concluye especificando que si bien, esta región del país, como lo es Cúcuta y su área metropolitana, rige su economía en torno al comercio, del cual, solo una pequeña muestra del sector industrial, específicamente la de la arcilla, demostró que estaría interesada en la inclusión laboral de las personas con discapacidad, de acuerdo al ordenamiento jurídico, que avala los beneficios tributarios planteados desde la vigencia del 2007.

Solo desde hace muy poco, este beneficio ha venido en alza en su aplicación, brindando apoyo a esta población menos favorecida, incentivando sus gastos, costos, rentas exentas e ingresos no constitutivos de renta ni de ganancia ocasional, de tal forma, que de acuerdo al impacto que generan sus transacciones comerciales especificamente los ingresos ordinarios, se pueda tener a través de una sólida y estratégica planeación tributaria y estructura contable razonable de los mismo, una disminución del impuestos a pagar y una población que se va a ver favorecida debido a la inclusión laboral de este sector tan importante en la economía de departamento.

El factor, considerado relevante en esta investigación es la contratación laboral de personas con discapacidad para que surja efectos tributarios, pero según la percepción errada de los empresarios en Colombia es que tienen la idea ceñida que esta clase de personas son por decirlo las menos rendidoras laboralmente, lo que resulta injusto y descabellada esta determinación ya que desconoce arbitrariamente el principio de la igualdad, coartando la mentalidad de esta clase de personas que quieren salir adelante por medio de posibilidades de empleos. 


\section{EFECTOS TRIBUTARIOS DE LA INCLUSIÓN LABORAL DE PERSONAS CON DISCAPACIDAD EN LAS EMPRESAS DEL SECTOR DE LA ARCILLA DE CÚCUTA Y SU ÁREA METROPOLITANA}

Carlos Alberto Carrillo Pacheco - Betsy Zulay Rondón Niño

Por otro lado, en Colombia existe un ordenamiento jurídico de carácter general que analizándola detenidamente, resultan muy poco efectivas en su aplicación, ya que estas son de carácter netamente sustantivo y no procedimental, lo que conlleva a que la norma publicada no es de carácter coercitivo, sino opcional, lo que implicaría determinar políticas fiscales más contundentes, ligadas a las demás rentas para que no se puedan filtrar alternativas laborales a esta clase de personas menos favorecidas. Como se mencionó anteriormente la palabra beneficio, se encuentra ligada íntimamente al principio de favorabilidad, lo que se deduce que estas clases de normas deber ir en beneficio de una población y no de un sector empresarial, si bien es cierto que los empresarios en Colombia son los que dinamizan el capital de la sociedad en general, son la personas por su mano de obra motor de la obtención de recursos y por ende impacto en sus tributos que van en pro de una sociedad en general, no en particular.

Como se puede evidenciar en el estudio, en Colombia se adolece de un registro y caracterización de las personas con discapacidad, problema que se evidencia, con la falta de políticas públicas que abarquen a toda la población que se encuentra en esta situación.

A partir de ahí, las políticas y normas tributarias no han sido suficientes, revelando que en las empresas del sector de la industria de la arcilla, dichas normas, no cumplen con las expectativas de las necesidad de la inclusión laboral de las personas con discapacidad en Cúcuta y su área metropolitana.

Falta una revisión de las leyes políticas en el ámbito tributario, debido a que las empresas tienen una alta carga impositiva, además la demás la situación socioeconómica de la ciudad de Cúcuta y su área metropolitana, no permita que estas hagan parte de programas de inclusión laboral al no estar motivadas por la situación económica.

Para Finalizar, este análisis investigativo, el factor que paraliza la aplicación de los beneficios tributarios ofrecidos por la ley, es la falta asesoría en el tema, motivo por el cual resulto interesante determinar que una buena parte del sector objeto de análisis se encuentran están interesados en profundizar o integrarse en el tema, lo que resulta proporcionalmente benéfico a los intereses del empleador y del empleado, en este caso de las personas con discapacidad.

\section{REFERENCIAS:}

Avendaño C, W. (2012). Obtenido de Innovación : Un proceso Necesario para las pequeñas y Medianas Empresas del Municipio de san José de Cúcuta.Norte de Santander (Colombia): http://www.scielo.org.co/scielo.php?pid=S012063462012000100009\&script=sci_arttext

Avendaño C, W. (2012). Innovación : Un proceso Necesario para las pequeñas y Medianas Empresas del Municipio de san José de Cúcuta.Norte de Santander (Colombia). Revista de la Universidad de medellín., 22.

Beltran, J. c. (2010). Discapacidad en Colombia:Reto para la Inclusión en Capital Humano.

Camara de Comercio de Cúcuta. (2013). Estudio sobre la informalidad Empresarial en el municipio de Cúcuta. 4.

Constitución política de Colombia. (1991). Constitución política de Colombia. Bogotá: legis.

Convención Internacional sobre los derechos de las personas con discapacidad. (2006). Convención Internacional sobre los derechos de las personas con discapacidad.

Dane. (2010). Dane. Obtenido de https://www.dane.gov.co/index.php/es/poblaciony-registros-vitales/discapacidad/119demograficas/discapacidad/2848-discapacidadpor-departamentos

Dane. (Abril de 2015). Mercado Laboral Cúcuta AM. Obtenido http://www.dane.gov.co/index.php/mercadolaboral/empleo-y-desempleo

Dane. (abril de 2015). principales Indicadores del mercado Laboral. Recuperado el 20 de mayo de 2015, de http://www.dane.gov.co/files/investigaciones/bolet ines/ech/ech/bol_empleo_abr_15.pdf

Gonzalez, J. M. (2013). Recuperado el 15 de marzo de 2015, de Industria. Arcilla, participación del 12,8 $\%$ del PIB de Norte de Santander.

La opinión. (10 de Diciembre de 2013). Discapacitados piden trabajo y educación. Recuperado el 20 de Noviembre de 2014, de La opinión: Discapacitados piden trabajo y educación. (10 de 
ISSN: 1794-9920 Julio - Diciembre 2015

Volumen 15 Número 2 Año 2015 Págs. 117 - 130

diciembre de 2013). La Opinión, pág. 1 http://www.laopinion.com.co/demo/index.php?opti on $=$ com_content\&task=view\&id=433594\&ltemid= 3.

ley 1145 del 10 de julio de 2007. (s.f.). Diario Oficial 46.685 del 10 de julio de 2007.

Ley 1346 de 2009. (s.f.). Diario Oficial 47427 del 31 de Julio de 2009.

Ley 361 de 1997. (s.f.). Diario Oficial 42978 del 11 de febrero de 1997.

ley 590 de 2000. (s.f.). Obtenido de Diario Oficial 44078 de julio 12 de 2000.

Ministerio de hacienda. (2013). Obtenido de Marco Fiscal de Mediano Plazo 2013.: www.camara.gov.co/portal2011/gestordocumental/.../5496-capitulo-x

Ministerio de salud y protección social. (diciembre de 2013). Cifras de registro de la Discapacidad en Colombia. Recuperado el 14 de Abril de 2015, de http://www.minsalud.gov.co/sites/rid/Lists/Bibliote caDigital/RIDE/DE/PS/Cifras\%20Registro\%20de \%20discapacidad\%20\%28Dic\%202013\%29.pdf

Mosharrof, H. (2014). Avanza inclusion socio-laboral. Obtenido de https://avanzainclusion.wordpress.com/2014/05/1 2/padre-mecanico-formador-empresario-ydiscapacitado-en-ese-orden/

Pacto deProductividad. (2014). Pacto de Productividad. Recuperado el 20 de febrero de 2015, de http://pactodeproductividad.com/pdf/ 